\title{
Reflexões teóricas e conceituais sobre política pública e governança aplicada ao contexto das Áreas Naturais Protegidas
}

\section{Theoretical and conceptual reflections about governance and public policy applied to Protected Natural Areas context}

RESUMO: Os acontecimentos internacionais referente aos efeitos causados entre a relação homem e meio ambiente influenciaram, de certa forma, no contexto da política pública ambiental brasileira, no qual, passou-se a discutir em pautas de agendas públicas a questão ambiental, inserindo-se assim, a temática de forma gradual na legislação do Brasil. Nesse sentido, houveram contribuições para a instituição de áreas naturais protegidas e consequentemente sentiu-se a necessidade de estabelecer uma boa governança nessas áreas. Dessa forma, o objetivo desta pesquisa é realizar uma reflexão teórica e conceitual sobre política pública e governança com aplicabilidade no contexto de áreas naturais protegidas, principalmente, abordar também a respeito da efetivação da gestão nas UC's. Como procedimento metodológico foi utilizado da pesquisa bibliográfica, a abordagem do estudo consiste em qualitativa e exploratória. Nessa perspectiva, é relevante a compreensão a abordagem conceitual sobre política pública e governança para assim aplicar no contexto das áreas naturais protegidas, onde observou-se que a política pública ambiental caminhou a passos lentos no Brasil, sobretudo, em virtude de interesses políticos econômicos do contexto histórico. Com a instituição do SNUC houve um maior fortalecimento da perspectiva de uso sustentável dos recursos naturais, das medidas compensatórias e da descentralização mais controlada da política no campo do meio ambiente no Brasil, incentivando a governança também descentralizada. No entanto, mesmo com o regimento da legislação do SNUC, por meio de algumas pesquisas empíricas, pode-se perceber que a efetivação da governança em UC's permeia-se por dificuldades e entraves.

PALAVRAS-CHAVE: Política Pública; Governança; Áreas Naturais Protegidas. 


\section{ABSTRACT}

International events concerning the effects between the man and the environment influenced, to some extent, in the context of the brazilian environmental public policy, in which, discussing in public the agendas guidelines environmental issue, inserting-if so, the theme gradually in law of Brazil. In this sense, there were contributions to the institution of protected natural áreas and therefore felt the need to establish good governance in these areas. Thus, the objective of this research is to conduct a theoretical and conceptual reflection on public policy and governance with applicability in the context of protected natural areas, mainly addressing also regarding the completion of the management in UC's. As methodological procedure was used in the bibliographical research, the approach of the study consists of qualitative and exploratory. In this respect, it is relevant to understanding the conceptual approach on governance and public policy to apply in the contexto protected natural areas, where it was observed that public environmental policy walked the slow steps in Brazil above all, because of economic and political interests of the historical context. With the establishment of a greater strengthening of SNUC there was prospect of use sustainable use of natural resources, the compensatory measures and decentralization more controlled in policy environment in Brazil, encouraging also decentralized governance. However, even with the regiment of the SNUC law, through some empirical research one can notice that the completion of the governance at UC's permeates by difficulties and obstacles.

KEYWORDS: Public Policy; Governance; Protected Natural Areas.

\section{Introdução}

A influência da política pública no contexto da sociedade está diretamente relacionada com a necessidade de resolução de problemas e desafios de caráter público e que possui abrangência coletiva. Dessa forma, a área da ciência política tem um papel relevante para a compreensão de fenômenos de natureza político-administrativa e como instrumento de organização dos recursos, processos deliberativos na manutenção dos interesses presentes na sociedade.

Diante disso, para a compreensão do processo de estabelecimento de políticas públicas é necessário tratar das definições e das abordagens propostas por alguns pesquisadores da área, realizando assim uma discussão sobre a exclusividade ou não do poder do Estado para a elaboração de políticas públicas, e também trazendo uma reflexão conceitual sobre política pública e definição de atores que participam da sua formulação, além disso, versar sobre a integração nesse processo entre o poder público com a sociedade civil.

A articulação entre Estado e sociedade acontece por meio das ações dos atores políticos que são os indivíduos, grupos ou organizações que desempenham um papel relevante na arena política. De acordo com Secchi 
(2014) esses atores tem a capacidade de influenciar, direta ou indiretamente, o conteúdo e os resultados da política pública, sendo esses os responsáveis e influenciadores na decisão do que é abordado ou não na agenda política, elaboram propostas, tomam decisões, e os encarregados de realizar as ações nos diferentes setores da sociedade.

Nesse contexto, as políticas públicas podem interferir e intervir em diversos âmbitos, tais como, no campo da saúde, educação, segurança, gestão, planejamento urbano, turismo e meio ambiente, uma vez que, esses setores necessitam de atenção e dependem da capacidade do sistema político para o planejamento de ações e deliberações na resolução dos problemas públicos, além disso, destaca-se que a política pública possui caráter dinâmico e transversal aos setores de atuação, ou seja, o estabelecimento de uma política pode afetar diretamente ou indiretamente outros setores.

Nessa perspectiva, diante das características presentes no campo da política pública, relacionada a articulação de diferentes atores sociais intervindo e influenciando vários setores da sociedade, nota-se uma necessidade de compreensão dos processos deliberativos realizados por esses atores governamentais e não governamentais. É relevante também buscar o entendimento de como se organizam as instituições que conduz as políticas públicas. Sendo assim, segue-se a lógica da teoria da governança, na qual, são fundamentais o entendimento das ações de regulação e a forma de conduzir a sociedade e seus recursos, por meio de instituições e atores sociais (SCHNEIDER, 2005).

Desta maneira, a governança está diretamente relacionada a análise da estrutura institucionais, sobretudo, centrada nos processos de decisões e ações dos atores sociais, de acordo com Nóbrega (2014) esta ideia gerou uma nova conotação aos estudos da ciências políticas, humanas e sociais aplicadas, além disso, esta noção foi fortalecida por meio do processo de descentralização do poder público, quando houve um incentivo a transferência de responsabilidades, ou seja, a inserção do processo de gestão compartilhada, descentralizada entre iniciativa privada e terceiro setor.

Sendo assim, entende-se que a governança pode ser trabalhada em diferentes contextos, global, nacional, institucional e comunidade. A inserção da governança na vertente democrática tem como foco central a emancipação social e política, considerando que os processos associados à governança teriam como mérito estimular a organização da sociedade civil, promovendo, então, uma reorganização dos mecanismos de tomadas de decisões, abrindo espaços públicos de diálogo com a sociedade interessada na resolução de conflitos em contextos diversos (FREY, 2007).

Discutido os aspectos relacionados o contexto da governança no âmbito ambiental, especificamente em áreas naturais protegidas (ANP), o Conselho Gestor (CG), que possui a responsabilidade pela governança dessas áreas, caracteriza-se como um espaço público jurídico-institucional responsável pelo processo de tomada de decisão, sendo regido pela legislação do SNUC (Sistema Nacional de Unidades de Conservação), uma vez que, os atores sociais que fazem parte do CG possuem a incumbência de 
administrar os recursos, e buscam solucionar ou minimizar os impactos negativos que também são problemas coletivos da sociedade. Outra característica desse tipo de instância de governança é a busca por atingir os objetivos da ANP de forma participativa e democrática.

Desta forma, o objetivo central do presente artigo é realizar uma discussão teórica e conceitual sobre política pública e governança aplicada ao contexto das áreas naturais protegidas. No intuito de discorrer a respeito da conceituação de política pública, abordando suas características, modelos e tipologias, correlacionando com a teoria de governança no contexto das áreas naturais protegidas, onde observa-se que a busca pela resolução dos problemas ambientais e sociais provenientes de atividades de lazer e turismo desenvolvidas nessas áreas, tornou-se um desafio para política pública e gestão desses espaços.

No que concerne aos procedimentos metodológicos, a abordagem consiste em qualitativa e exploratória. Utilizou-se a pesquisa bibliográfica na temática e estudos relacionados a política pública, apresentando então, uma discussão teórica conceitual e as diferentes abordagens. Além disso, foi desenvolvido um aporte teórico sobre a teoria da governança e suas características, conceitos, tipologias, e buscou-se também apresentar dimensões de análises de governança de acordo com atores que trabalham nessa vertente, e por fim, foi possível aplicar as temáticas em estudo no contexto das áreas naturais protegidas.

Diante disso, os tópicos que serão discutidos nesse artigo possuem relações com as demandas vinculadas as atuais agendas públicas, em virtude dos efeitos negativos sofridos pela sociedade e o meio ambiente. Sendo assim, a política pública e a governança são apresentadas como ferramentas importantes para a resolução e minimização dos problemas ambientais e sociais, sobretudo, no contexto das áreas naturais protegidas.

\section{Políticas Públicas: Conceitos e Abordagens}

A política pública surgiu nos EUA como área do conhecimento e disciplina acadêmica buscando a realização de estudos sobre as ações desenvolvidas pelos governos, sem estabelecer relação acadêmica com teorias que retratam sobre o papel do Estado, diferentemente da tradição europeia, na qual, as pesquisas destinadas a área da política pública centrava-se na análise sobre o Estado e suas instituições, além de pesquisas que baseavam-se em teorias explicativas sobre o papel do Estado e do governo como produtor de políticas públicas. Dessa forma, torna-se interessante a compreensão do surgimento dessa área como conhecimento acadêmico para melhor entender suas características, bem como, diferentes visões conceituais, tipologias e abordagens (SOUZA, 2006).

Em se tratando de relação conceitual, Souza (2006, p.5) afirma que "não existe uma única, nem melhor, definição sobre o que seja política pública", o que tornou-se interessante a discussão, sobre os principais conceitos do que seja a política pública. Para Secchi (2014) a definição de política pública está relacionada a uma diretriz elaborada para 0 
enfrentamento de um problema público, além disso, na visão do autor, o estabelecimento para a elaboração de uma política pública deve estar relacionado ao tratamento e resolução de um problema considerado como coletivamente relevante para a sociedade, o problema coletivo é entendido na perspectiva do status quo que pode ser compreendido como a situação atual se encontra e quando existe a possibilidade e expectativa do alcance de uma melhoria no setor que encontra-se o problema.

Nessa perspectiva, Souza (2006) resume política pública como o campo do conhecimento que tem como intuito, ao mesmo tempo em que "coloca o governo em ação" e/ou também se dispõe a analisar essa ação e quando necessário, propõe mudanças no rumo ou curso dessas ações. Seguindo esse pensamento, de acordo com a autora citada, a política pública quando formulada constitui-se como forma que os governos de caráter democrático manifestam seus interesses e propósitos em plataformas eleitorais em programas e ações que provocam resultados perante a sociedade e realizam mudanças no mundo real.

Nóbrega (2006) contribui nessa discussão de política pública quando afirma que seu conceito é complexo e está relacionado a várias questões da sociedade, na economia, social, segurança, ambiental entre outras, a intervenção do Estado na sociedade, por meio de estratégias de planejamento. Além disso, a política pública possui como objetivo maior promover o bem-estar social e econômico por meio das ações do governo, sobretudo, está sujeita ao jogo de forças sociais e políticas da sociedade, onde esta lógica se configura como um roteiro de ações, em que, define-se qual problema deve ser solucionado de uma determinada sociedade, indicando ações e os instrumentos que deverão ser estabelecidos para alcançar o objetivo final.

Diante da discussão conceitual sobre a política pública nota-se que no campo da ciência política existem algumas particularidades que caracterizam sua concepção, como a intencionalidade de resolução de problema de ordem coletiva por meio de atores governamentais e influência de atores não governamentais, devendo ser encarada como uma construção coletiva dos interesses públicos, além disso, propõe-se a realizando ações que provocam mudanças nos diferentes setores da sociedade. Ressalta-se que a política pública possui o comprometimento do primeiro setor, sendo o Estado e o governo promotores de leis, o segundo setor com a influência da iniciativa privada, onde o mercado redireciona a economia e o terceiro setor com as diversas organizações não governamentais e associações, que de certa forma, participa e contribui para que a sociedade civil consiga expressar os interesses e principais problemas públicos.

No debate teórico sobre a política pública destaca-se a relevância do entendimento sobre o percurso da dinâmica política, ou seja, os processos deliberativos que determinam as ações que serão realizadas em determinado setor da sociedade pode mudar o caminho político, dessa forma, Lowi (1964, apud SECCHI, 2014) determinou quatro tipos de políticas públicas que auxilia para o processo analítico das políticas públicas, uma vez que, de acordo com Secchi (2014) "as tipologias de políticas públicas são formas de classificar os 
conteúdos, os atores, os estilos, as instituições, dentro de um processo de política pública".

Diante disso, torna-se interessante entender as características de cada tipo de política para a compreensão dos efeitos causados na sociedade e o porquê que os atores políticos decidem o estabelecimento dessas políticas.

Dentre as tipologias estabelecidas por Lowi (1964, apud SECCHI, 2014) estão à política Regulatória que consiste no estabelecimento do padrão de comportamentos, serviços ou produtos para atores públicos e privados, para o autor esse tipo de política se desenvolvem de acordo com uma dinâmica pluralista, na qual, a aprovação ou rejeição dessa diretriz está relacionada a proporção de forças dos atores e também os interesses que predominam na sociedade e no campo político, como exemplo desse gênero de política, existem as regras de segurança alimentar e códigos de trânsitos.

A segunda tipologia é a distributiva que gera benefícios concentrados para alguns grupos de atores e custos para toda a coletividade contribuinte, dessa forma, o desenvolvimento desse tipo de política ocorre em uma arena menos conflituosa, pois, os custos são distribuídos entre a coletividade, como exemplo, pode-se citar os subsídios e gratuidade de taxas para alguns usuários públicos que tenham esse direito. A política redistributiva provoca diversos conflitos, pois, seu gênero concede benefícios concentrados para algumas categorias de atores e implicam custos concentrados para outras categorias de grupos. Atinge maior número de pessoas e impõe perdas concretas em curto prazo para certos tipos de grupos sociais, e ao mesmo tempo em que, promove benefícios para outros no mesmo período de tempo, como exemplo clássico encontram-se as políticas que são as cotas raciais nas universidades públicas e sistema tributário. E a quarta são as políticas constitutivas, são aquelas que definem as competências, jurisdições e regras da disputa política e da elaboração de políticas públicas (SECCHI, 2014; SOUZA, 2006).

Sendo assim, de acordo com as tipologias de políticas públicas nota-se que cada tipo vai desenvolver diferentes formas de apoio ou rejeição social e que esses processos de disputas passam por diferentes interesses políticos e sociais e que podem provocar mudanças significativas na sociedade civil, dessa forma, podendo haver manifestações de aceitação ou não dos grupos sociais que, de certa forma, participa do processo político.

A política pública além de possuir diferentes tipologias relacionadas a forma de atuação e efeitos impactados na sociedade, apresenta-se também em duas abordagens distintas, e isso ocorre diante delimitações dos atores responsáveis pela elaboração da política. A primeira abordagem defendida por alguns pesquisadores é a estatista, onde considera-se que as políticas públicas são somente aquelas que é emanada por um ator estatal, ou seja, nessa concepção existe uma exclusividade estatal no ato de fazer política e é derivada da superioridade objetiva do Estado em fazer leis e a sociedade cumpra essas leis. A segunda abordagem é a chamada multicêntrica, em que se pressupõe que as organizações privadas, organizações não governamentais, redes políticas públicas e atores estatais, são protagonistas no estabelecimento das políticas (SECCHI, 2014; LIMA, 2012). 
Nesse contexto, para fim desse artigo, a abordagem multicêntrica é a que prevalece, pois, está visão multicêntrica dá subsídios a discussão da teoria de governança e também a redes de políticas públicas, onde o Estado e a sociedade se articulam em esquemas espontâneos e de forma horizontais para a solução de problemas públicos e elaboração de políticas públicas dos diversos setores da sociedade.

Nesse cenário, ressalta-se a importância do contexto onde as políticas públicas acontecem, posto que, são elaboradas em um cenário político e as instituições possuem relevância nesse campo.

Diante do pensamento da escola institucionalista tradicional, o termo instituição está relacionado a regras formais capaz de condicionar o comportamento dos indivíduos, sendo assim, as instituições políticas são regras constitucionais, como os estatutos e códigos legais, além disso, também fazem parte os regimes internos das arenas onde as políticas públicas são construídas. Outras contribuições a respeito da importância das instituições no contexto da política pública foram abordadas pela concepção do neoinstitucionalismo, onde parte-se do pressuposto que o comportamento e decisões dos atores não é totalmente condicionada pelas instituições, mas, depende do grau de consolidação do aparato institucional e ressalva que as regras informais também são essenciais para o entendimento da dinâmica política (SECCHI, 2014; FREY, 2007).

Nesse prisma, sintetizando o entendimento da relevância das instituições como regras e práticas formais e informais que fazem parte no contexto político, são nesses ambientes que as políticas públicas são instituídas, onde as instituições são capazes de influenciar na dinâmica política, sobretudo, nas ações dos atores, os responsáveis tomadores de decisões, os interesses e percepções pessoais para o enfrentamento de problemas públicos, determinam posições de poder dentro do campo político, tornando-se primordial na governança política, tendo em vista que, a governança política está relacionada com os processos deliberativos dos recursos públicos realizados por meio de atores políticos que são regidos por regras e normas institucionais.

\section{Governança: Aspectos Conceituais, Tipologias e Dimensões de Análise}

O termo da governança pública foi apresentado pelo Banco Mundial no final da década de 1980, sendo relacionado com as questões de administração pública, no qual, havia sido publicado no relatório "SubSaharan África: From Crisis to Sustainable Gowth". Nesse referido documento já se discutia sobre a crise da governança como um dos principais entraves da superação da pobreza da África Subsaariana, o que resultou em necessidades de mudanças, como reformas institucionais tornando o setor público com mais efetividade (BRASIL, 2014).

Nesse sentindo, o Banco Mundial apresentou outros relatórios com o intuito de discutir a questão conceitual da governança, onde no Relatório "Governance and Development" a governança é vista como a maneira como o poder é exercido na administração dos recursos econômicos e sociais do país 
com o intuito de promover o desenvolvimento socioeconômico. Nesse relatório, foram definidos três aspectos distintos de governança, o primeiro relacionado à forma de regime político; o segundo aspecto refere-se ao processo pela qual a autoridade é exercida na gestão de recursos econômicos e sociais; e o terceiro está ligado a capacidade dos governos de conceber, formular e implementar políticas e exercer suas funções. Além disso, outra concepção pertinente foi acrescentada no conceito de governança difundido pelo Banco Mundial, no qual, é destacada a questão da necessidade de uma forte participação da sociedade civil nos negócios públicos, todos diante do regimento da lei (BRASIL, 2014).

Diante disso, percebe-se que inicialmente o ponto de vista da governança pública constata um fator expressivo sobre o aparato estatal e a capacidade que os governos possuem de formular e implantar as políticas públicas perante a sociedade com vistas ao desenvolvimento econômico e social. Em seguida, nota-se a necessidade da participação da sociedade civil no envolvimento e discussão sobre os recursos e demandas coletivas.

Observa-se, então, uma nova conotação sobre governança pública referente não apenas ao aparelho do Estado e suas articulações, mas, um conceito contemporâneo de governança sugerido por Schneider (2005, p.6) "este não está mais limitado a condução estatal - o governo do Governo -, mas se aplica também ao governo, regulação e condução da sociedade por meio de instituições e atores sociais". Sendo assim, essa percepção de governança, de certa forma, faz uma ruptura no contexto tradicional da abordagem estadista, onde o papel do Estado é ser um órgão centralizador e exclusivo da criação, implementação de políticas públicas e unicamente responsável por processos deliberativos, uma vez que, as demais instituições e diferentes atores sociais, tais como, iniciativa privada, sociedade civil e organizações não governamentais são fundamentais influenciadores no campo da governança política.

Nesse aspecto conceitual, Marini e Martins (2014) contribuem na discussão ao ver a governança pública na perspectiva de um processo de geração de valor público por meio da capacidade e qualidade das instituições; da colaboração entre os atores públicos e privados na coprodução de serviços, políticas e bens públicos pensando na melhoria do desempenho.

Sendo assim, notando a relevância do funcionamento de forma integrativa e participativa entre os atores, sobretudo, nenhum dos elementos pode ser pensado de forma isolada no contexto da governança pública.

Corroborando, Pereira (2009) revela que a governança possui um sentindo amplo, devido à legitimidade das ações que está relacionado ao processo como se concretiza, ou seja, para a um processo real de governança se faz necessário a participação e integração dos demais grupos da sociedade para a elaboração e legitimação da tomada de decisão ou de uma política pública.

A governança é um tema que possui considerável discussão sobre sua conceituação, haja vista que, que sua aplicação pode ser realizada em diferentes contextos, diante disso, Hall (2011) classificou em seu estudo 
quatro tipos conceituais de governança, o autor contribui de forma relevante nessa vertente, onde, as tipologias se caracterizam como um instrumento analítico sobre os estudos relacionados ao campo político e sobre governança.

A primeira tipologia é a governança hierárquica - onde prioriza-se as estruturas estatais verticalmente integradas, sendo o modelo tradicional de governança do Estado, com a gestão pública centralizada e com relações hierarquizadas entre os diferentes níveis do controle. No entanto, esse tipo de governança passou por um enfraquecimento em virtude das mudanças ocorridas, tais como, a globalização e crescimento dos poderes políticos locais.

A segunda tipologia se caracteriza como governança comunitária, essa abordagem é influenciada pelo comunitarismo e sua contribuição em relação a maior participação e envolvimento direto dos cidadãos no processo da governança. Nessa abordagem de governança sugere que os problemas coletivos sejam solucionados com menor participação do Estado e do Governo, no tocante dessa tipologia destaca-se a relevância do capital social para se alcançar o desenvolvimento econômico e social.

Já sobre a tipologia a governança do mercado, destaca-se que essa sofreu influências da filosofia política neoliberal voltada para as considerações do nível adequado de intervenção do Estado em sistemas socioeconômicos. Nessa vertente, o mercado é visto como mecanismo de alocação de recursos mais eficientes e justos. Todavia, salienta-se que o Estado permitir que o mercado atue como uma forma de governança não quer dizer que o Governo deixe de influenciar o esse sistema, uma vez que, o mercado é visto como outro mecanismo de coordenação social básica.

E por fim, a governança em rede que consiste em um modelo onde existe uma parceria entre o público com privado que facilita a coordenação de interesses e da atribuição de recursos para alcançar uma maior eficiência nos objetivos. Essa tipologia parte do pressuposto que é necessário contribuir na interação e coordenação dos interesses públicos e privados e da atribuição dos recursos coletivos, para que assim, possa haver o alcance ideal com maior eficácia na implementação das políticas públicas (HALL, 2011).

As tipologias conceituais caracterizam os vários contextos e ambientes que a governança pode ser aplicada, já que, de acordo com cada cenário diferencia a forma de atuação, dinâmica, e consequentemente cada contexto apresentam características diferentes. Sobre isso, Hall (2011) em sua pesquisa identificou alguns elementos-chave presentes na discussão sobre governança contemporânea como se apresenta no Quadro 1. 
Quadro 1: Elementos e características da governança contemporânea.

Box 1: Elements and characteristics of contemporary governance.

\begin{tabular}{|l|l|}
\hline \multicolumn{1}{|c|}{$\begin{array}{c}\text { Elementos da governança } \\
\text { contemporânea }\end{array}$} & \multicolumn{1}{|c|}{ Características } \\
\hline Participação e Partilha de Poder & $\begin{array}{l}\text { A formulação de políticas públicas não é considerada } \\
\text { como domínio exclusivo dos reguladores. Mas os demais } \\
\text { atores participam do processo de política como parte da } \\
\text { parceria público privada. }\end{array}$ \\
\hline Integração Multi-nível & $\begin{array}{l}\text { Integração entre os diferentes níveis de governo devendo } \\
\text { ocorrer de forma horizontal e vertical envolvendo os } \\
\text { atores privados e públicos }\end{array}$ \\
\hline Diversidade e descentralização & $\begin{array}{l}\text { A tendência não é uma abordagem legislativa e } \\
\text { reguladora e sim uma gama de diversidade de } \\
\text { abordagem. }\end{array}$ \\
\hline Deliberação & $\begin{array}{l}\text { Incentivo para a participação do processo de deliberação } \\
\text { da parte público e privado }\end{array}$ \\
\hline Flexibilidade e Revisibilidade & $\begin{array}{l}\text { As medidas relacionadas às leis são frequentemente } \\
\text { aplicadas que depende de diretrizes flexíveis e padrões } \\
\text { abertos, ou seja, a flexibilidade permite mudanças de } \\
\text { padrões políticos. }\end{array}$ \\
\hline Experimentação & $\begin{array}{l}\text { Encorajamento da experimentação local nos processos } \\
\text { de governança, bem como na criação de conhecimento e } \\
\text { compartilhamento em conexão com vigilância multi-lateral } \\
\text { e intercâmbio de resultados. }\end{array}$ \\
\hline
\end{tabular}

Fonte: Adaptado a partir de Hall (2011).

Source: Adapted from Hall (2011).

Os elementos-chave apresentados por Hall (2011) são condizentes com a pesquisa realizada por Ruhane et al. (2010) a respeito de uma revisão de literatura sobre as dimensões mais representativas de governança utilizadas nas publicações, diante disso, os resultados apontaram que as seis características que são mais frequentes nas pesquisas sobre o conceito de governança são: a responsabilidade; transparência; participação; estrutura; eficácia; e poder, corroborando com os elementos apresentados por Hall (2011).

Ainda sobre os elementos principais da governança, Nóbrega (2014) contribui com a formulação de um fluxograma contendo os "Elementos de Governança", no qual, foram complementados com outras categorias para a construção de uma "Matriz de Analítica de Governança Das Instâncias Turísticas". Os elementos identificados pelo autor consistem em:

1) Processo Eletivo dos Integrantes da Instância: Investigar como houve o processo de escolha dos representantes da sociedade;

2) Equilíbrio da representatividade da Instância: Deve haver cooperação igualitária, ou seja, a representação de todos os setores da sociedade uniformemente para atingir os interesses dos diferentes grupos envolvidos num determinado setor;

3) Avaliação do Desempenho da Instância: Neste elemento será considerado três níveis distintos de análise, baixa, média e alta, sendo assim, a $1^{1}$ está relacionada à regularidade das reuniões não segue o planejamento 
definido pelo grupo, e assim, as ações planejadas são concretizadas em menos de $50 \%$.

4) Participação Qualitativa entre os membros: A participação será definida como baixa se caso o representante frequente esporadicamente as reuniões da instância; Média se o representante participar regularmente por acreditar na relevância do papel em discutir as ações; e alta o representante participe ativamente, além disso, cumpra o papel de formar e informar os demais integrantes do grupo;

5) Realização de avaliação sistemáticas do grupo: Relacionada a avaliação das ações planejadas e executadas, nesse sentido, entende-se como baixa se os representantes apenas retomem as questões deliberadas na última reunião realizada pela instância; Média está relacionado quando são retomadas as discussões anteriores e são determinados prazos executáveis para o cumprimento das ações; Alta quando é realizada reuniões específicas para a avaliação das ações do grupo no período de 6 meses;

6) Quantidade e qualidade das parcerias firmadas pela Instância: Elemento relacionado as parcerias instituídas na instância, sobretudo, sobre a qualidade desses arranjos. Dessa forma, considera-se Baixa se o representante não identifique nenhuma parceria efetuada entre a instituição que representa a instância; Média quando o representante identifique pelo menos 1 ação efetuada entre a instituição que representa e a instância; Alta se o representante identificar mais de 1 ação efetuada entra a instituição que representa e a instância em um período de 12 meses.

7) Disseminação e acesso das informações entre os integrantes da instância: $O$ último elemento relaciona-se a respeito a democratização de informações e fortalecimento da confiança entre o grupo, sendo assim, considera-se como Baixa caso o representante não tenha recebido informações deliberada pelo grupo; Média caso o representante receba informações, por escrito ou oralmente, apenas em ocasiões das reuniões; e Alta quando o representante receba sistematicamente as informações em tempo hábil das reuniões.

Diante disso, por meio da reflexão realizada a partir da apresentação dos elementos de governança, em especial, do autor Nóbrega (2014) onde o contexto é abordado sobre instância de governança turística, mas, devido a relevância e precisão desses elementos para o processo de gestão, entendese adequado para ser aplicado em outros ambientes além do setor turístico, principalmente, na governança das áreas naturais protegidas, pois, essas possuem a complexidade em sua gestão, e os mesmo elementos de governança são necessários para o desenvolvimento de uma gestão efetiva nessas áreas.

Nesse sentindo, as políticas públicas ambientais e a teoria da governança são fatores essenciais no contexto de áreas naturais protegidas, sendo visualizadas como ferramentas que contribuem para 0 desenvolvimento de uma gestão efetiva. O avanço da política pública no cenário ambiental trouxe contribuições para a instituição das ANP no Brasil, 
além disso, surgindo a necessidade de haver integração e participação de todos os setores da sociedade.

\section{Aplicabilidade da Política Pública e Efetivação da Governança em Áreas Naturais Protegidas}

A temática de política pública e governança pública podem ser visualizadas em diferentes setores da sociedade, pois, ambas possuem funções primordiais de garantir que as demandas e problemas públicos sejam solucionados utilizando-se de formas sustentáveis para o consumo dos recursos econômicos, sociais e ambientais.

Dessa forma, de acordo com Peccatiello (2011) existe uma relação direta entre a questão da problemática ambiental com as das políticas públicas, sobretudo, na perspectiva que as demandas sociais determinam as intervenções político administrativas, no qual, são realizadas por meio do aparato Estatal com a elaboração e determinação de políticas públicas a fim de resolver os dilemas do meio ambiente.

Nesse prisma, com a evolução do agravamento dos problemas com o meio ambiente, em virtude do acentuado desenvolvimento do meio urbano, bem como, a efemeridade do sistema político-econômico do capitalismo, onde os recursos naturais são extraídos com tamanha fugacidade gera-se uma escassez dos recursos e impactos ambientais. Diante disso, é nesse contexto de necessidade de controle e de equilíbrio que as políticas públicas ambientais intervêm.

No cenário brasileiro, a política ambiental sofreu influências do movimento internacional ambientalista a partir da década de 1960, como fator institucional e legislativo. Peccatiello (2011) relata que as políticas voltadas para esse campo evoluíram nas últimas quatro décadas do século XX. A título de melhor conhecimento sobre esse progresso foi elaborado o Quadro 2 (próxima página), onde há um resumo sobre as principais políticas ambientais e marcos relevantes para esse contexto até alcançar a instituição de áreas naturais protegidas.

Diante da apresentação do Quadro 2, nota-se os principais acontecimentos político-administrativo do Brasil relacionado ao meio ambiente, e percebe-se que inicialmente a intencionalidade surge por meio da busca de regulamentação dos recursos naturais em âmbito nacional, principalmente, diante da ampla diversidade natural do país. Além disso, destaca-se a evolução institucional das políticas públicas relacionadas ao meio ambiente, principalmente, com a criação de normas, decretos, leis e instituições responsáveis pela coordenação de elaboração de políticas voltadas para esse campo. 
Quadro 2: Principais acontecimentos para a política pública ambiental no Brasil.

Box 2: Main events for the public environmental policy in Brazil.

\begin{tabular}{|c|c|c|}
\hline Acontecimentos & Principais episódios & Intencionalidade \\
\hline $\begin{array}{l}\text { Criação de } \\
\text { Dispositivos } \\
\text { Legais }\end{array}$ & $\begin{array}{l}\text { Código das águas, } \\
\text { Código de mineração, } \\
\text { Código Florestal } \\
\text { (1934); Código de } \\
\text { Pesca (1938); }\end{array}$ & $\begin{array}{l}\text { Esses episódios registram a busca por regularização } \\
\text { da apropriação de cada recurso natural em âmbito } \\
\text { nacional, sobretudo, no período da urbanização e } \\
\text { industrialização. A criação de parte dos instrumentos } \\
\text { legais que daria suporte a criação de áreas protegidas } \\
\text { no Brasil. }\end{array}$ \\
\hline $\begin{array}{l}\text { Criação e } \\
\text { delimitação de } \\
\text { zonas naturais } \\
\quad \text { protegidas }\end{array}$ & $\begin{array}{l}\text { Parque Nacional do } \\
\text { Itatiaia (1937); Parque } \\
\text { Nacional do Iguaçu } \\
\text { (1939); }\end{array}$ & Criação de Zonas Naturais Protegidas \\
\hline $\begin{array}{l}\text { Criação de Órgão } \\
\text { especializado em } \\
\text { assuntos } \\
\text { ambientais }\end{array}$ & $\begin{array}{l}\text { Secretária } \\
\text { Meio } \quad \text { Ambiecial de } \\
\text { (SEMA) }\end{array}$ & $\begin{array}{l}\text { A SEMA se dedicava ao processo de evolução da } \\
\text { legislação e aos assuntos de demanda nacional, o } \\
\text { Governo concentra-se na agenda de comando e } \\
\text { controle, principalmente, relacionado a atividade } \\
\text { industrial. }\end{array}$ \\
\hline $\begin{array}{l}\text { Definição e } \\
\text { delimitação das } \\
\text { áreas industriais }\end{array}$ & $\begin{array}{l}\text { Desenvolvimento de } \\
\text { leis metropolitanas de } \\
\text { zoneamento industrial } \\
\text { e de proteção de } \\
\text { mananciais }\end{array}$ & $\begin{array}{l}\text { No decorrer desse período buscou-se um } \\
\text { ordenamento territorial por meio de instrumentos de } \\
\text { políticas preventivas dos impactos gerados pela } \\
\text { atividade econômica. }\end{array}$ \\
\hline $\begin{array}{l}\text { Avanço a nível } \\
\text { Institucional }\end{array}$ & $\begin{array}{l}\text { Política Nacional de } \\
\text { Meio Ambiente (Lei no } \\
6.938 \text { de } 31 / 08 / 81) \text {; } \\
\text { Ministério } \\
\text { Desenvolvimento } \\
\text { Urbano e Meio } \\
\text { Ambiente (1985); } \\
\text { Criação do Conselho } \\
\text { Nacional do Meio } \\
\text { Ambiente (CONAMA); } \\
\text { Criação do Sistema } \\
\text { Nacional de Meio } \\
\text { Ambiente (SISNAMA) }\end{array}$ & $\begin{array}{l}\text { O principal avanço foi em nível institucional, pois, } \\
\text { nesse período houve a criação de órgãos, leis e } \\
\text { Sistema Nacional, diretamente vinculado à presidência } \\
\text { da Republica. Além disso, nota-se uma maior } \\
\text { integração entre os três níveis de governo (Federal, } \\
\text { Estadual, e Municipal). }\end{array}$ \\
\hline $\begin{array}{l}\text { Promulgada a } \\
\text { Nova Constituição } \\
\text { Federal (1988) }\end{array}$ & $\begin{array}{l}\text { Capítulo sobre } \\
\text { Urbana Política } \\
\text { ambiente }\end{array}$ & $\begin{array}{l}\text { Este marco possui relevância para as questões } \\
\text { ambientais, uma vez que, pois, os municípios passam } \\
\text { a ter responsabilidades em relação ao meio urbano e } \\
\text { também passa a ser exigido estudos prévios de } \\
\text { impacto ambiental em obras, minimizando assim os } \\
\text { possíveis impactos no meio ambiente. }\end{array}$ \\
\hline $\begin{array}{l}\text { Criação de } \\
\text { Sistema Integrado } \\
\text { do Processo de } \\
\text { Criação e gestão } \\
\text { de áreas } \\
\text { protegidas }\end{array}$ & $\begin{array}{l}\text { Criação do SNUC - } \\
\text { Lei no 9.985/2000 }\end{array}$ & $\begin{array}{l}\text { Neste período foi marcado pela necessidade de } \\
\text { concepção de um sistema, que promovesse maior } \\
\text { ordenação no processo de criação e gestão das áreas } \\
\text { protegidas. }\end{array}$ \\
\hline
\end{tabular}

Fonte: Peccatiello (2011).

Source: Peccatiello (2011).

Nesse sentido, outro avanço significativo no caminhar da política ambiental e permanece relevante até os dias atuais, foi a criação do SNUC Lei $n^{\circ} 9.985 / 2000$, cujo propósito foi definir e estabelecer critérios, tipologias e normas para todo processo de criação, implantação e gestão das áreas naturais protegidas no Brasil, de acordo com Peccatiello (2011) a criação 
dessa lei veio fortalecer a perspectiva de uso sustentável dos recursos naturais, das medidas compensatórias e de uma descentralização mais controlada da política no campo do meio ambiente no Brasil.

No entanto, ressalta-se que o SNUC também estabeleceu categorias que permite o uso público e o desenvolvimento de atividades de lazer, recreação e a prática do ecoturismo nas áreas naturais protegidas, 0 ecoturismo é entendido por Costa (2012) como toda forma de turismo, no qual, a motivação principal dos turistas é a observação e a apreciação da natureza, bem como, as culturas tradicionais que prevalecem nas áreas naturais. O desenvolvimento dessa atividade deve ser realizado com um forte planejamento, sobretudo, uma gestão efetiva para que não ocorram maiores impactos ambientais e sociais. De acordo com o Ministério do Meio Ambiente o ecoturismo é visto como uma atividade passível de ser realizada nas APN, tendo em vista que esse pode e contribui com a manutenção, gestão e maior valorização dos recursos naturais (COELHO, 2006).

De acordo com Pires (2006) a atividade turística em ANP quando desenvolvido ambientalmente e socialmente responsável, como rege a diretriz do SNUC, pode proporcionar benefícios para a proteção ambiental e também desempenha um papel importante na conservação da natureza, visto que, 0 próprio turismo se apropria e necessita dos recursos naturais, culturais e paisagísticos que viabiliza a prática nessas áreas.

Dessa forma, com a instituição do SNUC preconiza-se um formato de gestão diferenciado do modelo centralizador, posto que, a lei incentiva a participação das comunidades e de todos os atores (públicos, privados e terceiro setor) que devem fazer parte da instância que administra das áreas. Os Conselhos Gestores- CG's, se caracterizam como um espaço público jurídico-institucional responsável pela administração das ANP, ressalta-se que - CG deve seguir todas as diretrizes do SNUC, sendo assim, as ações e atividades devem ser planejadas e implementadas de forma integrada, o que reforça o papel da governança nessas áreas, sobretudo, as diretrizes descritas no SNUC por possuir esse caráter de descentralização e integração que estimula a governança dessas áreas a serem realizadas em forma de redes.

Nesse sentindo, percebe-se que a vertente política da Lei ํo 9.985/2000 direcionou a gestão a conceber, planejar e implementar as ações de forma descentralizada e participativa, além disso, iniciou a questão do desenvolvimento de práticas turísticas e de lazer nesses ambientes, sendo assim, sobre governança em áreas naturais protegidas, Eagles (2013) relata que é importante para melhorar o estado ecológico do território e também para facilitar uma maior participação da sociedade civil na gestão das ANP, melhorar sua sustentabilidade em longo prazo.

Corroborando com Eagles (2013), o autor Graham et al. (2003) afirma que a integração do setor governamental com a base social local pode trazer benefícios na maneira de governança contribuindo então para a garantia de integração de todos os atores sociais que fazem parte do processo de tomadas de decisão na instância de governança das áreas naturais protegidas. 
De acordo com Graham et al. (2003) para atingir os objetivos propostos para a ANP, os CG's podem exercer uma série de diferentes tipos de poderes, tais como, de planejamento, regulação de poderes, controle de despesas, geração de receita, visto que, todos esses, podem ser utilizados de forma coerente com as diretrizes e normas que regem as áreas naturais protegidas, dessa forma, a governança, nesse cenário é o exercício responsável desses poderes por meio dos membros do CG para alcançar todos os objetivos político administrativo da ANP e minimizar os conflitos existentes.

No contexto de governança em áreas naturais protegidas Graham et al. (2003) desenvolveu uma lista de princípios de boa governança que contribui para facilitar os desafios de se manter uma boa administração de recursos nas ANP, visto que, os ambientes dessas áreas são frágeis e exige dos seus governantes maior atenção e comprometimento. Os princípios foram baseados numa concepção de boa governança apresentados no Quadro 3, sendo proposto, cinco pontos principais que se interconectam, e em alguns casos se sobrepõem, além disso, são utilizados para ferramenta analítica para avaliar a governanças nessas áreas.

Quadro 3: Princípios de Boa Governança para Áreas Naturais Protegidas.

Box 3: Principles of good governance for protected natural Areas. Princípios de Boa Governança para Áreas Naturais Protegidas

Legitimidade para decisão: Envolve direito a voz de todos os implicados; orientação ao consenso; existência de contexto de suporte democracia e de direitos humanos; grau apropriado de descentralização no ato de decisão: gestão participativa na tomada de decisão em áreas protegidas; participação dos cidadãos em todos os níveis de tomada de decisão relacionados as áreas protegidas; existência de associações civis e mídia independente; e alto nível de confiança entre os vários atores envolvidos

Direcionamento: Considera visão estratégica: conformidade com o direcionamento internacional relativo as áreas protegidas; existência de direcionamento legislativo (formal e de regras tradicionais): existência de sistemas nacionais de áreas protegidas e planos de gestão individualizados; demonstração de liderança efetiva.

Desempenho: Engloba a perspectiva de eficiência na consecução de objetivos; capacidade de execução das funções requeridas; capacidade de coordenação; capacidade de disponibilização de informações ao público sobre desempenho; responsabilidade e capacidade de lidar com as críticas da sociedade; monitoramento e avaliação: gestão adaptativa e dinâmica; gerenciamento de risco.

Responsabilidade/Credibilidade na prestação de contas: Tem como focos centrais: clareza na definição de responsabilidades e autoridade (quem presta contas de que, e a quem); coerência e visão: papel das lideranças políticas: existência de instituições públicas responsáveis por zelar pela prestação de contas; sociedade civil e mídia capazes de mobilizar demandas com este objetivo; e transparência,

Honestidade/Imparcialidade: Considera a existência de um contexto jurídico de apoio; imparcialidade, correção e eficácia na aplicação das normas relativas as áreas protegidas; equidade no processo de criação e gestão de áreas protegidas.

Fonte: Graham et al. (2003).

Source: Graham et al. (2003).

Dessa forma, como apresentado no Quadro 3, os princípios de boa governanças em ANP possui relevância no processo de construção de governança democrática, bem como, contribui com o direcionamento no planejamento de ações, como também no caminho de avaliação das ações e comportamento dos membros responsáveis pela governança. 
Diante disso, algumas pesquisas realizadas contribuíram com a aplicação desses princípios de boa governança em áreas naturais protegidas como ferramenta analítica para obter resultados sobre sua gestão. No estudo realizado por Irving et al. (2007) destaca-se que o ponto crucial para a efetivação dos espaços de governança em ANP em geral é que haja a percepção, por parte de todos os atores envolvidos, das incumbências e limitações dos CG's em diferentes esferas, pois, por meio da consciência clara de todos os envolvidos sobre seus poderes e limites inerentes as diferentes instâncias permitem que a governança se desenvolva de maneira mais efetiva, sobre as demandas de gestão, evitando assim desgastes desnecessários dos recursos econômicos, sociais e ambientais.

Além disso, Irving et al. (2007), destaca a relevância da competência, funções e objetivos definidos, o engajamento dos membros do CG na elaboração e avaliação de políticas e programas públicos, pois, esses expressam os reais interesses do coletivo que representam, e para que isso ocorra o processo de compartilhamento de informação é essencial, bem como, a participação de todos os envolvidos.

De acordo com Marinelli (2016) foi desenvolvido uma pesquisa pelo Instituto Chico Mendes da Conservação da Biodiversidade - ICMBio (2011) com cerca de $1 / 3$ das ANP brasileiras sobre a efetividade da governança de Conselhos Gestores e como resultados apontaram uma variação de problemas comuns nas práticas desse espaço de governança, tais como, $32 \%$ dos processos de constituição dos CG levam em média três a quatro anos para serem instituídos, e mesmo depois de criados, $6 \%$ deles podem estar inativos; $44 \%$ dos CG's em estudos não tem planejamento anual após os primeiros cinco meses do ano; $68 \%$ não tem contribuído efetivamente para a gestão das ANP e órgãos públicos são instituições relativamente pouco presente em reuniões dos CG's.

Sendo assim, esses dados mostram resultados de Conselhos gestores que possui a governança sem efetividade, o que de certa forma, contribui negativamente para 0 desenvolvimento dessas áreas e também comprometem seus recursos naturais.

\section{Considerações Finais}

A política pública ambiental brasileira sofreu influências dos movimentos ambientalistas de nível internacional, no qual chamou atenção em âmbito nacional, diante disso, eventos foram realizados com o intuito de discutir as relações ambientais e os impactos advindo desses, e aos poucos a questão ambiental foi se tornando pauta de agendas públicas. Contudo, notou-se que os principais acontecimentos, tais como, os primeiros dispositivos legais e instituições criadas para ordenar as políticas públicas do meio ambiente, e a instituição do SNUC, foram relevantes, pois, representa a inserção da política ambiental na legislação brasileira e a preocupação com o meio ambiente e consequentemente, favoreceu a garantia de proteção e gestão diferenciadas das áreas naturais. 
A instituição do SNUC marcou o direcionamento da gestão das áreas naturais protegidas, pois, por meio dessa lei pode-se visualizar a inserção da busca pelo compartilhamento das responsabilidades, a inclusão dos outros setores da sociedade, inclusive, a comunidade no processo de tomada de decisão sobre os interesses coletivos, além disso, no SNUC permite o desenvolvimento de atividades que contribui para a ANP, bem como as comunidades, como ecoturismo, recreação e lazer, uma vez que, essas atividades devem ser planejadas e geridas de acordo com as diretrizes estabelecidas na lei.

Sobre a efetivação da real governança em áreas naturais protegidas percebe-se que mesmo com princípios definidos para se realizar uma boa gestão e ter instrumentos que possui regulamentos e diretrizes para criação, implementação e gestão, nota-se em estudos empíricos apresentados que os CG's responsáveis pela administração das ANP ainda possuem entraves como falta de compromissos dos atores representantes do setor público; falta de participação dos membros e dificuldades para a efetivação dos CG, o que dificulta manter uma gestão estruturada nessas áreas.

Nesse cenário, é pertinente elucidar que a governança contempla a necessidade de um grau maior de interação e cooperação entre os diferentes atores com o Estado formando relações a fim de se alcançar melhor gestão e administração dos interesses coletivos, principalmente obter resultados satisfatórios em prol do desenvolvimento econômico e social em todos os setores e contextos que a governança for aplicada. Além disso, essas relações e integrações de cooperação entre os atores podem ser equivalente a uma estrutura em redes, essencialmente, no campo das políticas públicas, as redes representam uma forma de integração entre os atores públicos, privados e terceiro setor, no qual, no contexto das áreas naturais protegidas é pertinente que os responsáveis pela gestão caminhem e direcione a governança em redes.

Sobre pesquisas futuras, indica-se a compreensão e aplicabilidade de modelos de governança em UC's, a fim de identificar de maneira mais aprofundada qual a tipologia de governança é mais utilizada e que consegue alcançar maior efetividade em diferentes realidades e contextos de UC's, já que o presente artigo focou em apresentar aspectos conceituais.

\section{Referências}

BRASIL. Referencial para avaliação de governança em políticas públicas/Tribunal de Contas da União. Brasília: TCU,2014.

BRASIL. Lei no 9.985, de 18 de julho de 2000; Decreto n 4.340, de 22 de agosto de 2002.Sistema Nacional de Unidade de Conservação da Natureza - SNUC: 3. ed. aum. Brasília: MMA/SBF, 2003.52p.

COSTA, P.C. Ecoturismo. São Paulo: Aleph: 2002. 
EAGLES, P.F.; ROMAGOSA, F.; BUTEAU-DUITSCHAEVER, W.C.; HAVITZ, M.; GLOVER, T.D.; MCCUTCHEON, B. Good governance in protected areas: an evaluation of stakeholders perceptions in British Columbia and Ontario Provincial Parks. Journal of Sustainable Tourism, p. 60 - 79. 2013.

FREY, K. Governança Urbana e Participação Pública. RAC-Eletrônica, v.1, n.1, p. 136-150. 2007.

GRAHAM, J.; AMOS, B.; PLUMPTRE, T. Principles for Good Governance in the 21st Century. Ottawa, Canada: Policy Brief No. 15 - Institute On Governance. 2003.

HALL, M.C. A typology of governance and its implications for tourism policy analysis. Journal of Sustainable Tourism. V. 19, p, 1-21, 2011.

IRVING, M.A.; COZZOLINO, F.; FRAGELLI, C.; SANCHO, A. Governança e políticas públicas: desafios para gestão de parques nacionais no Brasil. In: Fontaine, G.; Vliet, G. V.; Pasquis, R. (Org.). Politicas ambientales y gobernabilidad en America Latina. p. 79-103. Quito: FLACSO. 2007.

LIMA, W.G. Política pública: discussão de conceitos. Interface, pp. 1 - 6. 2012.

LISA RUHANEN, N.S. Governance: a review and synthesis of the literatura. Tourism Review, p. 4 -16. 2010.

MARINELLI, C.E. Aprimoramento da governança no âmbito de conselhos gestores para a efetividade de unidades de conservação na Amazônia: fatores-chave, mecanismos e impactos. Tese do Programa de PósGraduação da Universidade de Brasilia. Brasília, DF, Brasil: UFB. 2016.

MATIAS-PEREIRA; J. Governança no setor público. São Paulo: Atlas, 2010.

NÓBREGA, W.R.M. Participação popular e as políticas públicas de turismo na Amazônia: O PROECOTUR no distrito de Mosqueiro, Belém - PA. Dissertação (Mestrado em Cultura \& Turismo) - Universidade Estadual de Santa Cruz,. Ilhéus, BA, Brasil. 2006.

NÓBREGA, W.R.M. Turismo e Políticas Públicas na Amazônia Brasileira: Instâncias de Governança e Desenvolvimento nos municípios de Santarém e Belterra, Oeste do Estado do Pará. Tese de Doutorado. Belém, PA, Brasil: Universidade Federal do Pará. 2012.

NÓBREGA, W.R.M.; FIGUEIREDO, S.L. Turismo e gestão pública: uma avaliação das instâncias de governança no Oeste do Estado do Pará. In: PIMENTEL, T.D. [et. Al] (org.). Gestão pública do Turismo no Brasil: Teorias, metodologias e aplicações. Caxias do Sul, RS: Educs.2014.

PECCATIELLO, A.F. Políticas públicas ambientais no Brasil: da administração dos recursos naturais (1930) à criação do Sistema Nacional de Unidades de Conservação (2000). Desenvolvimento e Meio Ambiente, pp. 71-82. 2011. 
PIRES, P.D. As Múltiplas Facetas e Implicações da Relação Turismo e Meio Ambiente. IV SeminTUR - Seminário de Pesquisa em Turismo do MERCOSUL, p. 1-17. 2006.

SCHNEIDER, V. Redes de políticas públicas. Civitas - Revista de Ciências Sociais, p.29 - 58. 2005.

SECCHI, L. (2014). Políticas públicas: conceitos, esquemas de análise, casos práticos. São Paulo: Cengage Learning. 2014.

SOUZA, C. Políticas Públicas: uma revisão da literatura. Sociologias, pp. 2045. 2006.

Agradecimentos: Esta pesquisa teve o apoio do CNPq (Conselho Nacional de Desenvolvimento Científico e Tecnológico)

Luana Dayse de Oliveira Ferreira: Universidade Federal do Rio Grande do Norte, Natal, RN, Brasil.

E-mail: luana.Idof2@hotmail.com

Link para o currículo Lattes: http://lattes.cnpq.br/8302837494399096

Wilker Ricardo de Mendonça Nóbrega: Universidade Federal do Rio Grande do Norte, Natal, RN, Brasil.

E-mail: wilkernobrega@yahoo.com.br

Link para o currículo Lattes: http://lattes.cnpq.br/0025142529544906

Data de submissão: 14 de fevereiro de 2018

Data de recebimento de correções: 22 de fevereiro de 2018

Data do aceite: 23 de março de 2018

Avaliado anonimamente 